\title{
Has Cox-2 a prognostic role in non-small-cell lung cancer? A systematic review of the literature with meta-analysis of the survival results
}

\section{Mascaux ${ }^{*, 1,7}$, B Martin', M Paesmans ${ }^{2}$, T Berghmans', M Dusart ${ }^{3}$, A Haller ${ }^{4}$, P Lothaire ${ }^{5}$, A-P Meert', J-J Lafitte ${ }^{6}$ and J-P Sculier}

'Department of Intensive Care and Thoracic Oncology, Institut Jules Bordet, Centre des Tumeurs de l'Université Libre de Bruxelles, B-I000 Brussels, Belgium; ${ }^{2}$ Data Centre, Institut Jules Bordet, Centre des Tumeurs de l'Université Libre de Bruxelles, B-1000 Brussels, Belgium; ${ }^{3}$ Department of Nuclear Medicine, Institut Jules Bordet, Centre des Tumeurs de I'Université Libre de Bruxelles, B-I 000 Brussels, Belgium; ${ }^{4}$ Department of Pathology, Institut Jules Bordet, Centre des Tumeurs de l'Université Libre de Bruxelles, B- 1000 Brussels, Belgium; ${ }^{5}$ Department of Surgery, Institut Jules Bordet, Centre des Tumeurs de l'Université Libre de Bruxelles, B-1000 Brussels, Belgium; ' Chest Department, CHU Calmette, F-59037 Lille, France

\begin{abstract}
Cyclooxygenase-2 (COX-2) is overexpressed in lung cancer, especially in adenocarcinoma (ADC). Our aim was to determine the prognostic value of COX-2 on survival in patients with lung cancer. Studies evaluating the survival impact of COX-2 in lung cancer, published until December 2005, were selected. Data for estimation of individual hazard ratios (HR) for survival were extracted from the publications and combined in a pooled HR. Among 14 eligible papers, all dealing with non-small-cell lung cancer, 10 provided results for meta-analysis of survival data (evaluable studies). Cyclooxygenase-2 positivity was associated with reduced survival, improved survival or no statistically significant impact in six, one and seven studies, respectively. Combined HR for the 10 evaluable studies (I 236 patients) was I.39 (95\% confidence intervals (Cl): 0.97-1.99). In stage I lung cancer (six evaluable studies, 554 patients), it was 1.64 (95\% Cl: I.2I - 2.24). No significant impact was shown in ADC. A slight detrimental effect on survival in patients with lung cancer is associated with COX-2 expression, but the statistical significance is not reached. This effect is statistically significant in stage I, suggesting that COX-2 expression could be useful at early stages to distinguish those with a worse prognosis.
\end{abstract}

British Journal of Cancer (2006) 95, | 39- |45. doi: I0.1038/sj.bjc.6603226 www.bjcancer.com

Published online 20 June 2006

(c) 2006 Cancer Research UK

Keywords: COX-2; lung cancer; meta-analysis; systematic review; survival; prognostic factor

Lung cancer is a major cause of death despite diagnostic and therapeutic improvements. The overall 5-year survival rate is around $10 \%$ (Boyle and Ferlay, 2005). Some independent prognostic factors for survival have already been identified. They include, for small cell lung cancer (SCLC): disease extent and performance status (PS) (Paesmans et al, 2000); for non-small-cell lung cancer (NSCLC): PS, stage and, with lower impact, age, sex and weight loss (Paesmans et al, 1995; Strauss, 1997). The biological factors involved in carcinogenesis should also be considered as potential survival prognostic factors. Some of them, like angiogenesis and factors reflecting proliferative state, have already been identified in patients with lung cancer (Kanters et al, 1995). In order to clarify the prognostic impact of other biological factors in lung cancer, our group has performed systematic reviews of the literature with meta-analyses. It allowed us to show that VEGF (Delmotte et al, 2002), microvessel density (Meert et al, 2002b), EGFR (Meert et al, 2002a), HER-2/Neu (Meert et al, 2003), Ki-67 (Martin et al, 2004), K-Ras (Mascaux et al, 2005a) and p53

\footnotetext{
*Correspondence: Dr C Mascaux; E-mail: celine.mascaux@bordet.be

${ }^{7}$ Research fellow FNRS (National Fund of Scientific Research), Belgium Received 22 February 2006; revised 17 May 2006; accepted 19 May 2006; published online 20 June 2006
}

(Steels et al, 2001) have a negative impact on survival, whereas Bcl-2 (Martin et al, 2003) is associated with a favourable survival effect, at least when studying their impact in univariate analysis.

Recent attention has been drawn to prostaglandins and cyclooxygenases (COX) with the discovery that colonic polyps in patients with familial adenomatous polyposis (FAP) are decreased after the administration of non-steroidal anti-inflammatory drugs (NSAIDs) (Waddell and Loughry, 1983). Cyclooxygenases are key enzymes in the conversion of arachidonic acid to prostaglandin and exist as two isoforms, COX-1 and COX-2 (Smith and Langenbach, 2001). Cyclooxygenase-1 is constitutively expressed in nearly all cell types and plays a central role in many normal physiological processes, such as cytoprotection of gastric mucosa. COX-2 is a highly inducible gene, activated by cytokines, growth factors, phorbol esters, oncogenes and chemical carcinogens (Smith and Langenbach, 2001). Overexpression of COX-2 has been reported in many human malignancies including head and neck carcinomas (Gallo et al, 2002; Lin et al, 2002), oesophagus (Lagorce et al, 2003), colon (Sinicrope and Gill, 2004), breast (Ranger et al, 2004), pancreas (Kokawa et al, 2001) and prostatic cancer (Edwards et al, 2004).

In NSCLC, an increase in COX-2 expression was detected both in adenocarcinomas (ADC) and in squamous cell carcinomas (SQCC), but at a higher level in ADC than in SQCC (Hida et al, 
1998; Wolff et al, 1998; Ochiai et al, 1999). Cyclooxygenase-2 expression was also increased in atypical adenomatous hyperplasia, a possible precursor of ADC (Hida et al, 1998; Wolff et al, 1998; Hosomi et al, 2000; Hasturk et al, 2002) and in severe dysplasia and in situ carcinoma, precursors of SQCC (Mascaux et al, 2005b). However, the literature remains controversial about the prognostic value of COX-2 for survival in patients with lung cancer. In order to clarify this question, we performed a systematic review of the literature with methodological assessment and meta-analysis.

\section{MATERIALS AND METHODS}

\section{Selection of the publications}

To be eligible for the systematic review, a study had to fulfil the following criteria: to deal only with lung cancer (any stage or histology), to analyse the association between COX-2 and survival, to assess COX-2 on the primary tumour (not on metastatic tissue or tissue adjacent to the tumour), to have been published as a full paper in English or French. Abstracts were excluded because they do not provide sufficient data to evaluate the methodology of the trial and/or to perform meta-analysis.

Studies were identified by an electronic search on Medline databank and using the following keywords: 'lung cancer', 'lung carcinoma', 'lung neoplasms', 'lung tumor', 'lung tumors', 'lung tumour', 'lung tumours', 'lung adenocarcinoma', 'lung squamous', 'NSCLC', 'non-small cell lung cancer', 'non small cell lung cancer', 'non-small cell lung carcinoma', 'non small cell lung carcinoma', 'SCLC', 'small cell lung cancer', 'small cell lung carcinoma', 'cyclooxygenase', 'cyclooxygenase-2', 'COX-2'. The bibliographies reported in all the identified studies were used to complete this search, which ended on December 2005.

\section{Methodological assessment}

To assess the methodology, each study report was read independently by 10 investigators. The participation of many readers was a guarantee for the correct interpretation of the articles. The methodological evaluation was scored according to the European Lung Cancer Working Party (ELCWP) scale previously published (Steels et al, 2001) and applied in other meta-analyses (Delmotte et al, 2002; Meert et al, 2002a, b, 2003; Martin et al, 2003, 2004; Mascaux et al, 2005a). Each item was assessed using an ordinal scale (possible values: $2,1,0$ ). A consensus was reached in regular meetings where at least two-thirds of the investigators needed to be present. As the assessed items were objective ones, a consensus was always obtained.

The overall score evaluated several dimensions of the methodology, grouped in four main categories: the scientific design, the description of laboratory methods used to identify COX-2 expression, the generalisability of the results and the analysis of the study data. Each category had a maximum score of 100 points, with a maximal theoretical score of 400 points. When an item was not applicable to a study, its value was not taken into account in the total of the concerned category. The final scores were expressed as percentages, ranging from 0 to $100 \%$, higher values reflecting better methodological quality. Studies included in the systematic review were called 'eligible', those providing sufficient data for the meta-analysis 'evaluable'. To be eligible, studies had to provide univariate survival analysis according to COX-2.

\section{Statistical methods}

A study was considered significant if the $P$-value for the statistical test, comparing survival distributions between the groups with and without COX-2 increase, was $<0.05$. A study was called respectively, 'positive' or 'negative' when COX-2 increase was identified as a significant favourable or unfavourable prognostic factor for survival. These studies were further called 'significant' ones. Finally, a study was called 'not significant' if no statistically significant difference between the two groups was detected.

The association between two continuous variables was measured by the Spearman rank correlation coefficient. Non-parametric tests were used to compare the distribution of the quality scores according to the value of a discrete variable (Mann-Whitney tests for dichotomic variables and Kruskal-Wallis tests for multiple classes variables).

For the quantitative aggregation of the survival results, we measured the impact of COX-2 increase on survival by hazard ratio (HR) between the two survival distributions. For each trial, this HR was estimated by a method depending on the data provided in the publication. The most accurate method consisted of extracting the estimated HR and its standard error (s.e.) from the reported results using two of the following parameters: the HR and its confidence interval (CI) or the $O-E$ statistic (difference between numbers of observed and expected events), and the log-rank statistic or its $P$-value. If these data were not available, the total number of events, the number of patients at risk in each group and the logrank statistic or its $P$-value were used to allow for an approximation of the HR estimate. Finally, if the only exploitable data were in the form of graphical representations of the survival distributions, survival rates at some specified times were extracted in order to reconstruct the $\mathrm{HR}$ estimate and its variance, with the assumption that the rate of patients censored was constant during the study follow-up (Parmar et al, 1998). If this last method was used, three independent persons read the curves to reduce inaccuracy in the extracted survival rates. The individual $\mathrm{HR}$ estimates were combined into an overall HR using Peto's method (Yusuf et al, 1985), which consisted of using a fixed-effect model assuming homogeneity of the individual true HRs. This assumption was tested by performing $\chi^{2}$ tests for heterogeneity. If the assumption of homogeneity had to be rejected, we used a random-effect model as a second analysis. By convention, an observed $\mathrm{HR}<1$ implied a better survival for the group with COX-2 increase. This impact of COX-2 on survival was considered statistically significant if the 95\% CI for the overall HR did not overlap 1.

When data about global survival of the entire patients' population were available, survival was analysed globally. If authors only reported the results separately for different subgroups, those results corresponding to different cohorts of patients were treated separately in the meta-analysis.

\section{RESULTS}

\section{Study selection and characteristics}

Fourteen publications, published between 1999 and 2005, were eligible for the systematic review (Achiwa et al, 1999; Hosomi et al, 2000; Khuri et al, 2001; Brabender et al, 2002; Kim et al, 2003; Ab' Saber et al, 2004; Araki et al, 2004; Lu et al, 2004; Yamaguchi et al, 2004; Brattstrom et al, 2005; Laga et al, 2005; Marrogi et al, 2005; Richardson et al, 2005; Yuan et al, 2005). These publications concerned different cohorts of patients. The total number of included patients was 1543 , ranging from 53 to 259 patients per study (median: 92). The main characteristics of the 14 eligible publications are reported in Table 1 . Nine were dealing with all types of NSCLC, four with ADC and one with large-cell carcinoma. Seven studies only concerned locoregional diseases (two studies concerned stages I-IIIA and four, stages I-IIIB), four only stage I disease and four all stages (I-IV).

Ten studies evaluated COX-2 expression by immunohistochemistry (IHC), two studies assessed COX-2 mRNA overexpression by reverse transcription-polymerase chain reaction (RT-PCR) in real time and the last two studies determined COX-2 gene amplification by in situ hybridisation. 
Table I Main characteristics and results of the eligible studies

\begin{tabular}{|c|c|c|c|c|c|c|c|c|c|c|}
\hline First author & Year & Histology & Stage & $\mathbf{N}$ pts & $\begin{array}{l}\text { Laboratory } \\
\text { method }\end{array}$ & $\begin{array}{l}\text { Antibody for } \\
\text { IHC, dilution }\end{array}$ & $\begin{array}{c}\text { Definition of } \\
\text { Cox-2 } \\
\text { positivity }\end{array}$ & HR estimation & Evaluable & $\begin{array}{c}\text { Survival } \\
\text { results }\end{array}$ \\
\hline Ab' Saber & 2004 & LC & $|-||| B$ & 61 & $\mathrm{IHC}$ & Dako, 50 & Score I & No data & No & Negative \\
\hline Achiwa & 1999 & ADC & $|-||| B$ & 130 & $\mathrm{IHC}$ & $\mathrm{IBL}, 25$ & I>ref & Surv. curves & Yes & NS \\
\hline Araki & 2004 & ADC & I & 71 & $I H C$ & Cayman, 500 & $>10 \%$ & Log rank & Yes & Negative \\
\hline Brabender & 2002 & NSCLC & $|-||| A$ & 89 & RT-PCR & & Ratio ref. & Surv. curves & Yes & Negative \\
\hline Brattstrom & 2004 & NSCLC & $I-I V$ & 53 & $I H C$ & SantaCruz, 1000 & $>67 \%+1$ & No data & No & NS \\
\hline Hosomi & 2000 & ADC & $|-||| B$ & 87 & $\mathrm{IHC}$ & $\mathrm{IBL}, 50$ & $>10 \%$ & No data & No & NS \\
\hline Khuri & 2001 & NSCLC & 1 & 160 & $\mathrm{ISH}$ & & $1 \%$ & Surv. curves & Yes & NS \\
\hline Kim & 2003 & NSCLC & $I-\| I A$ & 84 & $\mathrm{IHC}$ & Cayman, 100 & Score 2 & Surv. curves & Yes & Negative \\
\hline Laga & 2005 & NSCLC & $\mathrm{I}-\mathrm{IV}$ & 259 & $\mathrm{HHC}$ & Cayman, 150 & Score 3 & Surv. curves & Yes & NS \\
\hline Lu & 2004 & NSCLC & I & 94 & $\mathrm{ISH}$ & & $1 \%$ & $H R$ & Yes & Negative \\
\hline Marrogi & 2000 & NSCLC & I-IV & 106 & $\mathrm{HCC}$ & SantaCruz, 100 & Score 4 & No data & No & NS \\
\hline Richardson & 2005 & NSCLC & $I-I \mid I A$ & 172 & $\mathrm{IHC}$ & SantaCruz, 400 & $>50 \% *$ & Surv. curves & Yes & NS \\
\hline Yamaguchi & 2004 & ADC & $|-||| B$ & 117 & $\mathrm{HC}$ & Transduc., 100 & Score 5 & Log rank & Yes & Positive \\
\hline Yuan & 2005 & NSCLC & $I-I V$ & 60 & RT-PCR & & Ratio ref. & Surv. curves & Yes & Negative \\
\hline
\end{tabular}

Abbreviations:ADC, adenocarcinoma; HR, hazard ratio; IBL, Immuno-biological laboratory; IHC, immunohistochemistry; ISH, in situ hybridisation; N pts, number of patients; NSCLC, non-small-cell lung cancer; ref, reference; RT-PCR, reverse transcriptase-polymerase chain reaction; surv. curves, survival curves; LC, large cell; NS: non significative; Transduc: Transduction; score I: score from 0 to 8 without any explanation, positive $\geqslant 2$, I: intensity; score 2, 3, 4, 5: different scores with combination of percentage of positives cells and intensity, *: $>50 \%$ : thresehold = median of positivity for COX-2, which was $50 \%$. HR estimation: description of the methods used to estimate the individual HR according to the three different methods described in the statistics methodology (see statistical methods).

Among the 14 studies eligible for the systematic review, four (Hosomi et al, 2000; Ab' Saber et al, 2004; Brattstrom et al, 2005; Marrogi et al, 2005) were inevaluable for the meta-analysis owing to a lack of data in the publication, not allowing to calculate the individual $\mathrm{HR}$ and its variance.

\section{Study results report}

Six of the 14 studies identified COX-2 overexpression as a poor prognostic factor for survival (with five evaluable for the metaanalysis) whereas one reported that it was a good prognostic factor (evaluable for the meta-analysis). The seven other studies showed no statistically significant impact of COX-2 overexpression on survival (four evaluable for meta-analysis).

Overall, in NSCLC, the rates of COX-2 protein overexpression (detected by IHC), COX-2 mRNA expression (RT-PCR) and COX-2 gene amplification (detected by in situ hybridisation) were respectively, $62.4 \%$ (number of evaluable tumours $n=833$, $51.7 \%(n=149)$ and $59.8 \%(n=254)$. For ADC, IHC and ISH assessments reported were respectively, $69 \%$ of COX-2-positive tumours $(n=368)$ and $41.2 \%(n=34)$. The rates of positive tumours by IHC, RT-PCR and in situ hybridisation in stage I NSCLC were, respectively, 65\% $(n=240), 50 \%(n=60)$ and $59.8 \%$ $(n=254)$.

\section{Quality assessment}

The overall quality score ranged from 36.3 to $66.0 \%$ with a median of $51.5 \%$. No statistically significant quality difference was shown between significant and non-significant studies for the global score (median: 55.4 vs 48.9\%, $P=0.06$ ). There was also no statistically significant difference between evaluable and non-evaluable studies for meta-analysis in terms of global scores (51.5 vs 53.4\%, $P=0.78)$.

We performed the same analysis of the scores for the 10 studies evaluable for meta-analysis. Their overall quality score ranged between 41.8 and $66 \%$, with a median of $51.5 \%$. As previously observed among eligible publications, there was no statistically significant difference between significant and non-significant studies evaluable for the meta-analysis according to the global score (median of 54.6 vs $48.4 \%, P=0.09$ ).

\section{Meta-analysis}

The meta-analysis was performed on 10 studies (1236 patients) dealing with NSCLC, and were shown to have similar methodological scores.

The individual HRs of the 10 evaluable studies were calculated by one of the three methods reported in the Materials and Methods section according to available data. One study reported the data needed to directly calculate the estimated HR (95\% CI). In two trials, HR was approximated by the total number of events and the log-rank statistic. For the seven remaining studies, HR had to be extrapolated from the graphical representation of the survival distributions.

The results of the meta-analysis are reported in Table 2 and in Figure 3. Overall, COX-2 overexpression was not associated with a significant impact on survival. As the test for heterogeneity was highly significant $(P<0.001)$, we also applied a random-effect model in calculating the HR, which was 1.39 (95\% CI: $0.97-1.99$ ) (Figure 1).

Regarding subgroup analyses (Figure 3 ), we had the adequate data to aggregate the studies dealing with stage I, with ADC and according to the technique used to detect Cox-2. We first performed an interaction test to assess whether there might be a differential effect of COX-2 according to stage, histology or the technique. We found one significant interaction between COX-2 and stage $(P<0.01)$. When we aggregated the six studies (Achiwa et al, 1999; Khuri et al, 2001; Araki et al, 2004; Lu et al, 2004; Richardson et al, 2005; Yuan et al, 2005) giving separate results about stage I NSCLC, the combined HR was statistically significant by using the random-effect model: HR $1.64,95 \%$ CI $(1.21-2.24)$ as there was indeed a significant heterogeneity $(P=0.04)$ (Figure 2). We did not observe a statistically significant effect of COX-2 on survival in ADC (five evaluable studies) (Achiwa et al, 1999; Araki et al, 2004; Yamaguchi et al, 2004; Richardson et al, 2005; Yuan et al, 2005) with HR 1.35 (95\% CI 0.62-2.95) (random effect; test of heterogeneity $P<0.001$ ). We also found one significant interaction between COX-2 and the technique used for its detection $(P=0.003)$. The test of heterogeneity was significant for the IHC studies $(P=0.00001)$, but neither for RT - PCR studies $(P=0.1)$, nor, for ISH studies $(P=0.18)$. As the number of studies in the subgroups was small, we only report the HR estimated by the random effect because of a lack of power of the test of 
Table 2 Meta-analysis: HR value in NSCLC subgroups according to histology, stage

\begin{tabular}{lcclc}
\hline & Nb & Patients & $\chi^{\mathbf{2}}$ heterogeneity test & Random effects HR (95\% Cl) \\
\hline Overall & 10 & 1236 & $\mathbf{P}=\mathbf{0 . 0 0 0 0 0}$ & $1.39(0.97-1.99)$ \\
Stage I disease & 6 & 554 & $\mathbf{P}=\mathbf{0 . 0 4}$ & $\mathbf{1 . 6 4}(\mathbf{I . 2 I - 2 . 2 4 )}$ \\
Adenocarcinoma & 5 & 402 & $\mathbf{P}=\mathbf{0 . 0 0 0 0 0}$ & $1.35(0.62-2.95)$ \\
IHC & 6 & 833 & $\mathbf{P}=\mathbf{0 . 0 0 0 0}$ & $1.06(0.64-1.77)$ \\
RT-PCR & 2 & 149 & $P=0.1$ & $\mathbf{3 . 1 5}(\mathbf{I . 0 8 - 9 . 2 1 )}$ \\
ISH & 2 & 254 & $P=0.18$ & $1.40(0.94-2.07)$ \\
RT-PCR + ISH & 4 & 403 & $\mathbf{P}=\mathbf{0 . 0 3}$ & $1.31(0.97-1.76)$ \\
\hline
\end{tabular}

Abbreviations: HR, hazard ratio; IHC, immunohistochemistry; ISH, in situ hybridisation; Nb, number of studies; RT-PCR, reverse transcriptase-polymerase chain reaction Statistically significant results are in bold.

Achiwa et al (1999)

Araki et al (2004)

Brabender et al 2004

Khuri et al 2001

Kim et al 2003

Yuan et al 2005

Richardson et al 2005

Lu et al 2004

Laga et al 2005

Yamagushi et al 2004

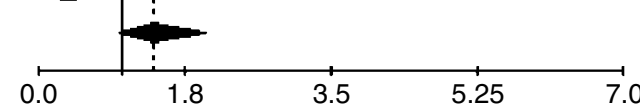

Figure I Meta-analysis of the 10 evaluable studies assessing COX-2 in NSCLC. Hazard ratio and $95 \% \mathrm{Cl}$ of survival in studies evaluating COX-2 status in NSCLC. HR> I implies a survival disadvantage for the group with COX-2 expression. The square size is proportional to the number of patients included in the study. The centre of the lozenge gives the combined HR of the meta-analysis and its extremities give the $95 \% \mathrm{Cl}$. $\mathrm{HR}=1.39 ; \mathrm{Cl} 95 \% 0.97-1.99$. Total number of patients: 1236 .

Achiwa et al (1999)

Araki et al (2004)

Khuri et al 2001

Lu et al 2004

Richardson et al 2005

Yuan et al 2005

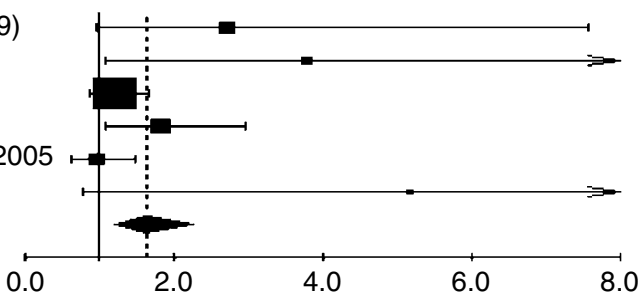

Figure 2 Meta-analysis of the six evaluable studies assessing COX-2 in stage I NSCLC. Hazard ratio and $95 \% \mathrm{Cl}$ of survival in studies evaluating COX-2 status in NSCLC. HR> I implies a survival disadvantage for the group with COX-2 expression. The square size is proportional to the number of patients included in the study. The centre of the lozenge gives the combined HR of the meta-analysis and its extremities give the $95 \% \mathrm{Cl}$. Hazard ratio $=1.64 ; \mathrm{Cl} 95 \%$ I.2I-2.24. Total number of patients: 554 .

heterogeneity. The HRs were the following: for the six studies with IHC (833 patients) 1.06 (95\% CI $0.64-1.77)$, for the two RT - PCR studies (149 patients) 3.15 (1.08-9.21), for the two ISH studies (254 patients) $1.40(0.94-2.07)$ and for RT - PCR and ISH studies together (403 patients) $1.31(0.97-1.76)$.

\section{DISCUSSION}

The present systematic review of the literature about the impact of COX-2 overexpression on survival in lung cancer found a slight role of COX-2 on overall survival in NSCLC, without not reaching statistical significance. When the analysis was restricted to stage I

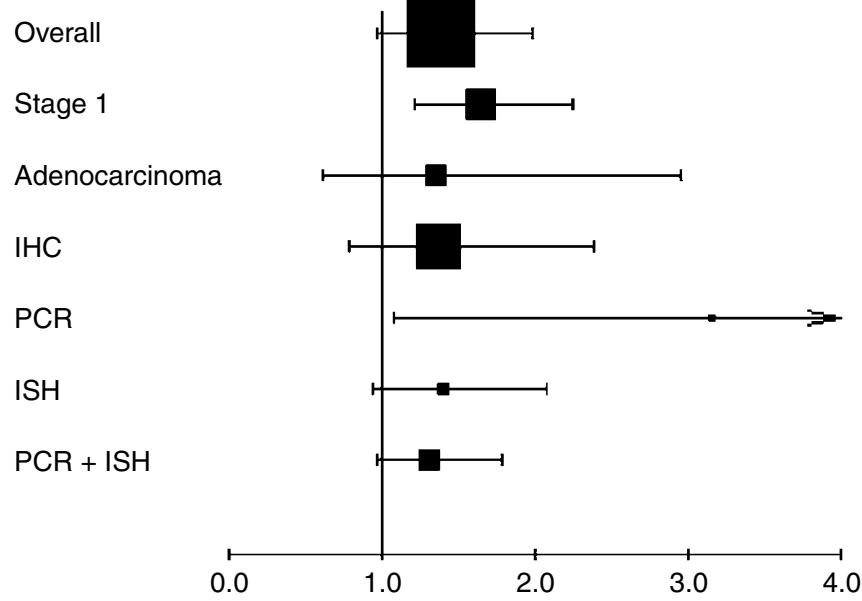

Figure 3 Overall and subgroup analyses. Hazard ratio and $95 \% \mathrm{Cl}$ of survival in studies evaluating COX-2 status in NSCLC. HR> I implies a survival disadvantage for the group with COX-2 expression. The square size is proportional to the number of patients included in the study and its extremities gives the $95 \% \mathrm{Cl}$. The Figure 3 shows that there is a trend for a pejorative role of COX-2 as a prognostic survival in NSCLC and that the results become significant ( $\mathrm{Cl}$ not crossing I) for the subgroups of stage I and of RT-PCR.

NSCLC, we observed a statistically significant detrimental effect of COX-2 on survival, suggesting that this prognostic factor could be of importance in early-stage NSCLC. In subgroup analysis according to the different techniques used to detect COX-2, results were only significant with RT-PCR.

The search for a potential prognostic role of COX-2 in survival for patients with lung cancer is based on its frequent overexpression in NSCLC and also on its potential interference with most pathways implicated in lung carcinogenesis. The role of COX-2 in oncogenesis has widely been studied by in vitro experiments and by in vivo analyses based on animal models. In lung cancer, COX-2 overexpression is associated with microvascular angiogenesis (Masferrer et al, 2000) and resistance to apoptosis (Liu et al, 1998; Hida et al, 2000). Cyclooxygenase-2 overexpression also decreases host immunity (Huang et al, 1998) and alters cell adhesion with enhancement of invasion and metastasis (Tsujii et al, 1997). Despite all these experimental observations, our meta-analysis failed to demonstrate in univariate analysis a statistically significant impact of COX-2 expression as a prognostic factor for overall survival in patients with NSCLC. In subgroup analysis, we observed a significant effect in stage I NSCLC. Cyclooxygenase-2 overexpression might modify the prognosis of early-stage NSCLC: early lung cancer overexpressing COX-2 would be more aggressive and would have a worse prognosis than those without COX-2 abnormality. These data could be helpful to determine among stage I diseases those who 
could benefit from a more aggressive treatment. But the present results concerning the prognostic role of COX-2 in stage I NSCLC still need to be confirmed by adequately designed prospective studies with multivariate analysis before a potential clinical application.

It should be noted that COX-2 appears early in oncogenesis for SQCC (Mascaux et al, 2005b) as well as for ADC (Hida et al, 1998; Wolff et al, 1998; Hosomi et al, 2000; Hasturk et al, 2002). In a previous study (Mascaux et al, 2005b), we observed that COX-2 expression increases in bronchial preneoplastic lesions at the stage of severe dysplasia and particularly in clones of cells showing atypia: this suggests an active role of COX-2 in bronchial epithelial cells transformation to malignancy. These data could partially explain the prognostic role of COX-2 at stage I, its impact being lost at later steps because of the potential interaction with many factors.

Our analysis had to deal with heterogeneity problems. There was a highly significant heterogeneity among the 10 evaluable studies included in the meta-analysis. This could be explained by the type of patients and the disease characteristics, or by the diversity in the techniques used to identify alteration of COX-2 status. Only six evaluable studies used IHC, two ISH and two RT - PCR. The results of subgroup analysis according to the technique used to detect COX-2 support this hypothesis. Results for the six IHC studies were not significant and a high heterogeneity was detected between the studies $(P=0.003)$. This heterogeneity could be explained by the fact that the technique of IHC is not comparable among the six studies. The primary antibodies were different and so was the revelation protocols, and different levels of positivity $(0,10,50 \%$, different scores combining intensity and percentage, intensity only) were used. As another example, when ISH and RT - PCR (two different techniques assessing RNA) studies were aggregated together, the heterogeneity increased $(P=0.03)$ as compared with ISH alone $(P=0.18)$ or RT - PCR alone $(P=0.1)$, and with only a few studies, the results were statistically significant for the RT PCR subgroup, which is the most standardised technique. It is thus very important to use a well-defined and well-standardised technique to be reproducible for the evaluation of biological markers. Particularly, the protocol of IHC should be the same between different laboratories (same antibody, same revelation protocol ( $\mathrm{pH}$ and compounds of the solutions, heating method etc) and same criteria of evaluation for the positivity of the marker) so that the results could be compared and eventually, aggregated.

Some other biases could be due to the methodology used to perform our systematic review. We performed a methodological assessment of the studies to avoid some selection biases (more detailed reports of significant trials), as we performed in prior studies about biological prognostic factors in lung cancer (Steels et al, 2001). The absence of a detectable difference in quality score between significant and non-significant studies, and between evaluable and non-evaluable studies, encourages us to perform a quantitative aggregation (meta-analysis) of the results of the individual trials. However, in the present review, numbers of studies are small, preventing us to analyse any potential difference between significant and non-significant, or evaluable and nonevaluable studies. However, this approach does not prevent all potential biases. Publication bias, choice of language, selection of fully published studies only, method of extrapolation of $\mathrm{HR}$, validity of a meta-analysis based on systematic review of the literature as compared with those based on individual data were already discussed in our previous papers (Steels et al, 2001).
Some eligible trials had to be excluded from the meta-analysis because they did not provide sufficient data on survival. Among the four excluded studies, only one $(25 \%)$ was statistically significant, whereas a higher proportion of the studies evaluable for the meta-analysis were significant $(60 \%)$. It is known that negative studies are less frequently published or, if they are, with less detailed results, making them less assessable. The methodological quality of trials, according to the global score, was not significantly different between evaluable and non-evaluable studies for the quantitative aggregation of individual survival results. Nevertheless, such an approach does not fully protect a potential bias owing to the impossibility taking into account all the studies with negative or non-significant results.

Our meta-analysis is based on published data collected by a systematic review of the literature and can only be performed by univariate analysis. This is a limit to this type of work, which appears thus as a preliminary step before performing multivariate studies. Many interesting data arise from multivariate analyses and particularly from proteomic and genomic wide screen analysis, which is probably the way of the future. But if microarrays is an interesting technique providing very meaningful data, it should be kept in mind that it remains a research screening technique and that it could not be applied in routine because of the high price.

It should also be noted that COX-2 expression increases in patient treated by taxanes (Subbaramaiah et al, 2003; Altorki et al, 2005), providing an argument to treat patients with lung cancer by an association of taxanes and anti-COX-2 drugs. The studies analysing COX-2 expression after a specific treatment were not included in this meta-analysis because treated and untreated tumours do not have the same biological behaviour and should not be aggregated together. This topic, COX-2 expression in pretreated lung tumours, should be the topic of another systematic review.

In conclusion, when all stages and histologies are considered, there is a trend for COX-2 overexpression as a prognostic factor for survival in patients with NSCLC, but there is a high heterogeneity between the studies and these results are not statistically significant. Interestingly, our meta-analysis showed with more evidence that COX-2 has a detrimental effect on survival in stage I NSCLC. This prognostic role of COX-2 at earliest stage of NSCLC could be of clinical interest in the selection of the patients eligible for induction or adjuvant chemotherapy. Hazard ratio was also significant for the studies using RT-PCR and not for those using IHC, suggesting that a better standardisation of the technique to define and to detect COX-2 positivity is required to the generalisability of the results. Our results need to be confirmed by an adequately designed prospective study and the exact role of COX-2 overexpression needs to be determined by an appropriate multivariate analysis taking into account the classical well-defined (at the moment of the study) prognostic factors for lung cancer such as PS, stage, age, sex, weight loss.

\section{ACKNOWLEDGEMENTS}

Dr Céline Mascaux was supported by a fellowship from National Fund for Scientific Research. This study was also supported by a grant from the FNRS (FRSM; 3.4624.04), a grant from 'TélévieFNRS' (7.4529.04) and a grant from the ASBL 'Les Amis de l'Institut Jules Bordet'.

\section{REFERENCES}

Ab' Saber AM, Massoni Neto LM, Bianchi CP, Ctenas BB, Parra ER, Eher EM, Pereira JC, Takagaki T, Yamaguchi NH, Capelozzi VL (2004) 
Achiwa H, Yatabe Y, Hida T, Kuroishi T, Kozaki K, Nakamura S, Ogawa M, Sugiura T, Mitsudomi T, Takahashi T (1999) Prognostic significance of elevated cyclooxygenase 2 expression in primary, resected lung adenocarcinomas. Clin Cancer Res 5: 1001-1005

Altorki NK, Port JL, Zhang F, Golijanin D, Thaler HT, Duffield-Lillico AJ, Subbaramaiah K, Dannenberg AJ (2005) Chemotherapy induces the expression of cyclooxygenase-2 in non-small cell lung cancer. Clin Cancer Res 11: $4191-4197$

Araki K, Hashimoto K, Ardyanto TD, Osaki M, Shomori K, Nakamura H, Ito $\mathrm{H}$ (2004) Co-expression of Cox-2 and EGFR in stage I human bronchial adenocarcinomas. Lung Cancer 45: 161-169

Boyle P, Ferlay J (2005) Cancer incidence and mortality in Europe, 2004. Ann Oncol 16: $481-488$

Brabender J, Park J, Metzger R, Schneider PM, Lord RV, Holscher AH, Danenberg KD, Danenberg PV (2002) Prognostic significance of cyclooxygenase 2 mRNA expression in non-small cell lung cancer. Ann Surg 235: $440-443$

Brattstrom D, Wester K, Bergqvist $\mathrm{M}$, Hesselius $\mathrm{P}$, Malmstrom PE, Wagenius G, Brodin O (2005) HER-2, EGFR, COX-2 expression status correlated to microvessel density and survival in resected non-small cell Lung cancer. Acta Oncol 43: 80-86

Delmotte P, Martin B, Paesmans M, Berghmans T, Mascaux C, Meert AP, Steels E, Verdebout JM, Lafitte JJ, Sculier JP (2002) [VEGF and survival of patients with lung cancer: a systematic literature review and metaanalysis]. Rev Mal Respir 19: 577-584

Edwards J, Mukherjee R, Munro AF, Wells AC, Almushatat A, Bartlett JM (2004) HER2 and COX2 expression in human prostate cancer. Eur J Cancer 40: $50-55$

Gallo O, Masini E, Bianchi B, Bruschini L, Paglierani M, Franchi A (2002) Prognostic significance of cyclooxygenase-2 pathway and angiogenesis in head and neck squamous cell carcinoma. Hum Pathol 33: 708-714

Hasturk S, Kemp B, Kalapurakal SK, Kurie JM, Hong WK, Lee JS (2002) Expression of cyclooxygenase-1 and cyclooxygenase-2 in bronchial epithelium and nonsmall cell lung carcinoma. Cancer 94: 1023-1031

Hida T, Kozaki K, Muramatsu H, Masuda A, Shimizu S, Mitsudomi T, Sugiura T, Ogawa M, Takahashi T (2000) Cyclooxygenase-2 inhibitor induces apoptosis and enhances cytotoxicity of various anticancer agents in non-small cell lung cancer cell lines. Clin Cancer Res 6: 2006-2011

Hida T, Yatabe Y, Achiwa H, Muramatsu H, Kozaki K, Nakamura S, Ogawa M, Mitsudomi T, Sugiura T, Takahashi T (1998) Increased expression of cyclooxygenase 2 occurs frequently in human lung cancers, specifically in adenocarcinomas. Cancer Res 58: $3761-3764$

Hosomi Y, Yokose T, Hirose Y, Nakajima R, Nagai K, Nishiwaki Y, Ochiai A (2000) Increased cyclooxygenase 2 (COX-2) expression occurs frequently in precursor lesions of human adenocarcinoma of the lung. Lung Cancer 30: $73-81$

Huang M, Stolina M, Sharma S, Mao JT, Zhu L, Miller PW, Wollman J, Herschman H, Dubinett SM (1998) Non-small cell lung cancer cyclooxygenase-2-dependent regulation of cytokine balance in lymphocytes and macrophages: up-regulation of interleukin 10 and downregulation of interleukin 12 production. Cancer Res 58: 1208-1216

Kanters SD, Lammers JW, Voest EE (1995) Molecular and biological factores in the prognosis of non-small cell lung cancer. Eur Respir J 8: $1389-1397$

Khuri FR, Wu H, Lee JJ, Kemp BL, Lotan R, Lippman SM, Feng L, Hong WK, Xu XC (2001) Cyclooxygenase-2 overexpression is a marker of poor prognosis in stage I non-small cell lung cancer. Clin Cancer Res 7: $861-867$

Kim HS, Youm HR, Lee JS, Min KW, Chung JH, Park CS (2003) Correlation between cyclooxygenase-2 and tumor angiogenesis in non-small cell lung cancer. Lung Cancer 42: 163 - 170

Kokawa A, Kondo H, Gotoda T, Ono H, Saito D, Nakadaira S, Kosuge T, Yoshida S (2001) Increased expression of cyclooxygenase-2 in human pancreatic neoplasms and potential for chemoprevention by cyclooxygenase inhibitors. Cancer 91: 333-338

Laga AC, Zander DS, Cagle PT (2005) Prognostic significance of cyclooxygenase 2 expression in 259 cases of non-small cell lung cancer. Arch Pathol Lab Med 129: 1113-1117

Lagorce C, Paraf F, Vidaud D, Couvelard A, Wendum D, Martin A, Flejou JF (2003) Cyclooxygenase-2 is expressed frequently and early in Barrett's oesophagus and associated adenocarcinoma. Histopathology 42: 457-465

Lin DT, Subbaramaiah K, Shah JP, Dannenberg AJ, Boyle JO (2002) Cyclooxygenase-2: a novel molecular target for the prevention and treatment of head and neck cancer. Head Neck 24: 792-799
Liu XH, Yao S, Kirschenbaum A, Levine AC (1998) NS398, a selective cyclooxygenase-2 inhibitor, induces apoptosis and down-regulates bcl-2 expression in LNCaP cells. Cancer Res 58: $4245-4249$

Lu C, Soria JC, Tang X, Xu XC, Wang L, Mao L, Lotan R, Kemp B, Bekele BN, Feng L, Hong WK, Khuri FR (2004) Prognostic factors in resected stage I non-small-cell lung cancer: a multivariate analysis of six molecular markers. J Clin Oncol 22: 4575-4583

Marrogi AJ, Travis WD, Welsh JA, Khan MA, Rahim $\mathrm{H}$, Tazelaar $\mathrm{H}$, Pairolero P, Trastek V, Jett J, Caporaso NE, LIotta LA, Harris CC (2005) Nitric oxide synthase, cyclooxygenase 2, and vascular endothelial growth factor in the angiogenesis of non-small cell lung carcinoma. Clin Cancer Res 6: $4739-4744$

Martin B, Paesmans M, Berghmans T, Branle F, Ghisdal L, Mascaux C, Meert AP, Steels E, Vallot F, Verdebout JM, Lafitte JJ, Sculier JP (2003) Role of $\mathrm{Bcl}-2$ as a prognostic factor for survival in lung cancer: a systematic review of the literature with meta-analysis. $\mathrm{Br} J$ Cancer 89: $55-64$

Martin B, Paesmans M, Mascaux C, Berghmans T, Lothaire P, Meert AP, Lafitte JJ, Sculier JP (2004) Ki-67 expression and patients survival in lung cancer: systematic review of the literature with meta-analysis. Br J Cancer 91: $2018-2025$

Mascaux C, Iannino N, Martin B, Paesmans M, Berghmans T, Dusart M, Haller A, Lothaire P, Meert AP, Noel S, Lafitte JJ, Sculier JP (2005a) The role of $R A S$ oncogene in survival of patients with lung cancer: a systematic review of the literature with meta-analysis. $B r$ J Cancer 92: $131-139$

Mascaux C, Martin B, Verdebout JM, Ninane V, Sculier JP (2005b) COX-2 expression during early lung squamous cell carcinoma oncogenesis. Eur Respir J 26: $198-203$

Masferrer JL, Leahy KM, Koki AT, Zweifel BS, Settle SL, Woerner BM, Edwards DA, Flickinger AG, Moore RJ, Seibert K (2000) Antiangiogenic and antitumor activities of cyclooxygenase-2 inhibitors. Cancer Res 60: $1306-1311$

Meert AP, Martin B, Delmotte P, Berghmans T, Lafitte JJ, Mascaux C, Paesmans M, Steels E, Verdebout JM, Sculier JP (2002a) The role of EGF$\mathrm{R}$ expression on patient survival in lung cancer: a systematic review with meta-analysis. Eur Respir J 20: 975 -981

Meert AP, Martin B, Paesmans M, Berghmans T, Mascaux C, Verdebout JM, Delmotte P, Lafitte JJ, Sculier JP (2003) The role of HER-2/neu expression on the survival of patients with lung cancer: a systematic review of the literature. Br I Cancer 89: 959-965

Meert AP, Paesmans M, Martin B, Delmotte P, Berghmans T, Verdebout JM, Lafitte JJ, Mascaux C, Sculier JP (2002b) The role of microvesse density on the survival of patients with lung cancer: a systematic review of the literature with meta-analysis. $\mathrm{Br} J$ Cancer 87: $694-701$

Ochiai M, Oguri T, Isobe T, Ishioka S, Yamakido M (1999) Cyclooxygenase2 (COX-2) mRNA expression levels in normal lung tissues and non-small cell lung cancers. Jpn J Cancer Res 90: 1338-1343

Paesmans M, Sculier J-P, Lecomtre J, Thiriaux J, Libert P, Sergysels R, Bureau G, Dabouis G, Van Custem O, Mommen P, Ninane V, Klastersky J, for the European Lung Cancer Working Party (2000) Prognostic factors in patients with small cell lung cancer: analysis of a series of 763 patients included in four consecutive prospective trials and with a minimal 5-year follow-up duration. Cancer 89: $523-533$

Paesmans M, Sculier J-P, Libert P, Bureau G, Dabouis G, Thiriaux J, Michel J, Van Custem O, Sergysels R, Mommen P (1995) Prognostic factors for survival in advanced non-small cell lung cancer: univariate and multivariate analyses including recursive partitioning and amalgamation algorithms in 1052 patients. J Clin Oncol 13: 1221-1230

Parmar MK, Torri V, Stewart L (1998) Extracting summary statistics to perform meta-analyses of the published literature for survival endpoints. Stat Med 17: 2815-2834

Ranger GS, Thomas V, Jewell A, Mokbel K (2004) Elevated cyclooxygenase2 expression correlates with distant metastases in breast cancer. Anticancer Res 24: 2349-2351

Richardson CM, Richardson D, Swinson DE, Swain WA, Cox G, O'Byrne KJ (2005) Cyclooxygenase-2 protein levels are independent of epidermal growth factor receptor expression or activation in operable non-small cell lung cancer. Lung Cancer 48: 47-57

Sinicrope FA, Gill S (2004) Role of cyclooxygenase-2 in colorectal cancer Cancer Metast Rev 23: 63-75

Smith WL, Langenbach R (2001) Why there are two cyclooxygenase isozymes. J Clin Invest 107: 1491 - 1495 
Steels E, Paesmans M, Berghmans T, Branle F, Lemaitre F, Mascaux C, Meert AP, Vallot F, Lafitte JJ, Sculier JP (2001) Role of p53 as a prognostic factor for survival in lung cancer: a systematic review of the literature with a meta-analysis. Eur Respir $J$ 18: $705-719$

Strauss GM (1997) Prognostic markers in resectable non-small cell lung cancer. Hematol Oncol Clin N Am 11: 409-434

Subbaramaiah K, Marmo TP, Dixon DA, Dannenberg AJ (2003) Regulation of cyclooxgenase- 2 mRNA stability by taxanes: evidence for involvement of p38, MAPKAPK-2, and HuR. J Biol Chem 278: $37637-37647$

Tsujii M, Kawano S, Dubois RN (1997) Cyclooxygenase-2 expression in human colon cancer cells increases metastatic potential. Proc Natl Acad Sci USA 94: 3336-3340

Waddell WR, Loughry RW (1983) Sulindac for polyposis of the colon. J Surg Oncol 24: 83-87
Wolff H, Saukkonen K, Anttila S, Karjalainen A, Vainio H, Ristimaki A (1998) Expression of cyclooxygenase-2 in human lung carcinoma. Cancer Res 58: $4997-5001$

Yamaguchi NH, Lichtenfels AJ, Demarchi LM, da Silva AP, Garippo AL, Alves VF, Michelin C, Azevedo PM, Moya T, Takagaki T, Saldiva PH, Vollmer RT, Capelozzi VL (2004) COX-2, MMP-9, and Noguchi classification provide additional prognostic information about adenocarcinoma of the lung. A study of 117 patients from Brazil. Am J Clin Pathol 121: 78-86

Yuan A, Yu CJ, Shun CT, Luh KT, Kuo SH, Lee YC, Yang PC (2005) Total cyclooxygenase-2 mRNA levels correlate with vascular endothelial growth factor mRNA levels, tumor angiogenesis and prognosis in nonsmall cell lung cancer patients. Int J Cancer 115: 545-555

Yusuf S, Peto R, Lewis J, Collins R, Sleight P (1985) Blockade during and after myocardial infarction: an overview of the randomized trials. Prog Cardiovasc Dis 27: $335-371$ 